\title{
Effect of Length of Cellulose Nanofibers on Mechanical Reinforcement of Polyvinyl Alcohol
}

\author{
Mengxia Wang ${ }^{1}$, Xiaran Miao ${ }^{2,3, *} \mathbb{0}$, Hui Li ${ }^{1, *}$ and Chunhai Chen ${ }^{1}$ \\ 1 Center for Advanced Low-Dimension Materials, State Key Laboratory for Modification of Chemical Fibers \\ and Polymer Materials, College of Material Science and Engineering, Donghua University, \\ Shanghai 201620, China; 2180257@mail.dhu.edu.cn (M.W.); cch2018@jlu.edu.cn (C.C.) \\ 2 Shanghai Synchrotron Radiation Facility, Shanghai Advanced Research Institute, \\ Chinese Academy of Sciences, Shanghai 201204, China \\ 3 Shanghai Institute of Applied Physics, Chinese Academy of Sciences, Shanghai 201800, China \\ * Correspondence: miaoxiaran@zjlab.org.cn (X.M.); lihui@dhu.edu.cn (H.L.); Tel.: +86-21-20304851
}

check for updates

Citation: Wang, M.; Miao, X.; Li, H.; Chen, C. Effect of Length of Cellulose Nanofibers on Mechanical

Reinforcement of Polyvinyl Alcohol. Polymers 2022, 14, 128. https:// doi.org/10.3390/polym14010128 Academic Editors: Zhen Zhang Jin Huang and Huiyang Bian

Received: 16 November 2021 Accepted: 20 December 2021 Published: 30 December 2021

Publisher's Note: MDPI stays neutral with regard to jurisdictional claims in published maps and institutional affiliations.

Copyright: (C) 2021 by the authors. Licensee MDPI, Basel, Switzerland. This article is an open access article distributed under the terms and conditions of the Creative Commons Attribution (CC BY) license (https:// creativecommons.org/licenses/by/ $4.0 /)$.

\begin{abstract}
Cellulose nanofibers (CNF), representing the nano-structured cellulose, have attained an extensive research attention due to their sustainability, biodegradability, nanoscale dimensions, large surface area, unique optical and mechanical performance, etc. Different lengths of CNF can lead to different extents of entanglements or network-like structures through van der Waals forces. In this study, a series of polyvinyl alcohol (PVA) composite films, reinforced with CNF of different lengths, were fabricated via conventional solvent casting technique. CNF were extracted from jute fibers by tuning the dosage of sodium hypochlorite during the TEMPO-mediated oxidation. The mechanical properties and thermal behavior were observed to be significantly improved, while the optical transparency decreased slightly (Tr. > 75\%). Interestingly, the PVA/CNF20 nanocomposite films exhibited higher tensile strength of $34.22 \mathrm{MPa}$ at $2 \mathrm{wt} \%$ filler loading than the PVA/CNF10 (32.55 MPa) while displayed higher elastic modulus of $482.75 \mathrm{MPa}$ than the PVA/CNF20 films (405.80 MPa). Overall, the findings reported in this study provide a novel, simple and inexpensive approach for preparing the high-performance polymer nanocomposites with tunable mechanical properties, reinforced with an abundant and renewable material.
\end{abstract}

Keywords: TEMPO-mediated oxidized cellulose nanofibrils; morphology and dimension; reinforcement; polyvinyl alcohol

\section{Introduction}

Nanotechnology has impacted the wide areas such as medicine, electronics and food technology by manipulating the nanomaterials for various purposes [1-5]. The material development has significant improved owing to the incorporation of nanotechnology. In recent years, the use of nanomaterials as nano-reinforcement in the polymer composites has been widely reported [6,7]. The nanoscale fibers used for reinforcing the polymer matrices represent an important class of nano-reinforcements [8-10]. The fibers are dispersed at nanoscale, thus, a significantly less filler fraction is needed as compared to the conventional reinforcing materials, while the properties of composites are markedly improved [11,12]. To minimize the environmental health and safety concerns, the sustainable and environmentally friendly development of nanomaterials is highly desired [13,14]. One of the most promising strategies for the sustainable development involving nanotechnology is the isolation of nanomaterials from low-cost, abundant, renewable and biodegradable resources [15]. Thus, the green nanomaterials have received major attention recently, thus, enhancing the development of natural and renewable products [16,17].

Nanocellulose possesses valuable characteristics such as a renewability and biodegradability with satisfactory mechanical properties when incorporated in a polymer matrix [18-20]. Owing to the depletion of the raw materials to develop the synthetic polymers, the use 
of nanocellulose as biopolymer reinforcing agent can be promising [21-24]. The literature studies reveal that research interest in the nanocomposites consisting of nanocellulose and polymer matrices has significantly enhanced in recent years. The reported increment in the tensile properties, crystallinity index and specific surface area of the composites successfully demonstrate the potential use of nanocellulose as reinforcement for developing the polymer nanocomposites [25-28]. Overall, nanocellulose represents a superior eco-friendly material as compared with the inorganic nanoscale materials used as reinforcements [29,30]. However, a few challenges exist with respect to the use of nanocellulose in polymers for achieving good performance, including the efficient dispersion of particles in the matrix, compatibility of nano-reinforcement in the matrix and development of suitable methods for the material processing, which also determining the final properties of the cellulose nanocomposites $[21,24,25]$.

With respect to the mechanical properties of the nanocellulose-based nanocomposites, regardless of the type of polymer matrix or processing method, the addition of nanocellulose as a reinforcement phase in the polymer matrices can improve the mechanical performance of the resulting materials. A number of studies have reported that the addition of nanocellulose in the polymer matrices leads to an enhanced tensile modulus of the materials, which is attributed to the geometry and stiffness of nanocellulose [31-33]. In addition, the enhancement in the mechanical properties also corresponds to the strong interactions between the matrix and nanocellulose, which restrict the movement of the polymer chains, thereby hindering its deformation [22,34]. Apart from mechanical properties, several studies have shown that the incorporation of nanocellulose can also improve the thermal properties of the materials [35-37]. Generally, the thermal stability of the polymer nanocomposites has been reported to increase with the incorporation of nanocellulose, which is attributed to the restricted mobility of the polymer chains due to the addition of nanocellulose as well as the homogeneous distribution of nanocellulose in the polymer matrix $[22,24,34,38]$.

Cellulose nanofibrils with different size presents different surface charge, dimension, morphology, and crystal structure, which precisely make CNF-based materials possess distinct properties and performances. Yang et al. produced cellulose nanofibrils with different lengths by the high-pressure homogenization and the results showed that the short cellulose nanofibril exhibited higher hydrophobicity and low interfacial tension [31]. Isogai et al. found self-standing films manufactured by longer cellulose nanofibrils displayed obviously higher tensile strengths, elongations at break and crystallinity indexes [32]. Besides, Wu et al. proposed that cellulose fibril with large size had higher ice recrystallization inhibition (IRI) activity [33]. These typical results apparently demonstrated that composites enhancing by cellulose nanofibril with various sizes could showcase significantly different properties as well. Moreover, polyvinyl alcohol (PVA), a water-soluble crystalline polymer, has extensive prospects in the fields of food packaging film materials, textile, artificial organs and medical gels biomedical fields, etc, which predominantly put down to its biodegradability, biocompatibility, excellent film-forming properties and gas barrier properties [39-41]. PVA is normally used composites to lower down the cost of product without any compromise or partial compromise with its properties and the hydrophilic composition, which consists of hydroxyl groups in the PVA structure, is well-linked with carbohydrates, creating significant agreement in composites [40,42,43].

To the best of our knowledge, the previous studies have primarily concentrated on the impact of nanocellulose on the optical transparency, morphological properties and mechanical properties of the nanocomposites, and the effect of the CNF length at nanoscale on the mechanical properties has been rarely studied. In this study, three kinds of CNF with different dimensions were isolated from jute fibers by tuning the dosage of sodium hypochlorite during the TEMPO-mediated oxidation, and the CNF reinforced PVA composites were fabricated via the conventional solvent casting/evaporation technique. The surface charge, morphology, physical properties and crystallinity index of CNF were successively characterized, and the impact of CNF length as well as the evolution of the 
multi-level microstructure in the nanocellulose-based composites during stretching were studied to explore the mechanism of reinforcement by nanocellulose, so as to provide an effective reference for the subsequent preparation of nano-matrix composites with higher performance.

\section{Materials and Methods}

\subsection{Materials}

The pristine jute fibers were provided by Redbud Textile Tech. Inc., Suzhou, China. The fibers were sufficiently dried in a vacuum drying oven at $70{ }^{\circ} \mathrm{C}$ for over $24 \mathrm{~h}$. Polyvinyl alcohol with a degree of alcoholysis of $97.0-98.8 \mathrm{~mol} \%$ was procured from Shanghai Yuanye Biological Technology Co. Ltd. (Shanghai, China) 2,2,6,6-tetrmethylpiperidine1-oxyl radical (TEMPO, 98\%), sodium bromide $(\mathrm{NaBr}, 99.6 \%)$ and sodium hypochlorite ( $\mathrm{NaClO}, 6-14 \%$ ) were supplied by Shanghai Macklin Biochemical Co. Ltd. (Shanghai, China) and were used as received. The sodium hydroxide $(\mathrm{NaOH}, \geq 96.0 \%)$ and ethanol were purchased from Shanghai Titan Scientific Co. Ltd. and utilized without any further purification. All reagents were of analytical grade, and ultrapure water generated using the Milli-Q plus water purification system (Millipore Corporation, Billerica, MA, USA) was used.

\subsection{Preparation of CNF of Different Sizes}

The jute fibers were alkali treated by using $3 \mathrm{wt} \% \mathrm{NaOH}$ solution at $70{ }^{\circ} \mathrm{C}$ for 4 to remove a majority of lignin, hemicellulose and pectin. Subsequently, the pre-treated jute fibers were filtered and washed for several times with deionized water, followed by drying in a vacuum oven at $80^{\circ} \mathrm{C}$ for $6 \mathrm{~h}$. The preparation of CNF by the TEMPO-mediated catalytic oxidation has been reported in detail by Isogai et al. [44,45]. Briefly, $1 \mathrm{~g}$ alkalized jute fibers were dispersed in $100 \mathrm{~mL}$ deionized water. The suspension was stirred for $1 \mathrm{~h}$, followed by the addition of $\mathrm{NaBr}(0.33 \mathrm{~g})$ and TEMPO $(0.033 \mathrm{~g})$. It is particularly emphasized that the morphology and size of CNF can be changed by adding different contents of $\mathrm{NaClO}$ into the system, which is also the most important point different from other studies $[29,30]$. The $\mathrm{NaClO}$ solutions $(20 \mathrm{~g} / 10 \mathrm{~g} / 5 \mathrm{~g})$ were subsequently added to the suspension to initiate the reaction at room temperature. The $\mathrm{pH}$ of the mixture was maintained between 10.6 and 10.8 by adding $1 \mathrm{wt} \% \mathrm{NaOH}$ solution. The reaction was terminated by adding ethanol $(7.0 \mathrm{~mL})$ until the $\mathrm{pH}$ of the system no longer changed. The translucent jelly-like $\mathrm{CNF}$ were obtained after repeated centrifugal washing, which were denoted as CNF20, CNF10 and CNF5, respectively. Later, the resulting CNF were stored at $4{ }^{\circ} \mathrm{C}$ without any treatment for subsequent utilization.

\subsection{Preparation of $P V A / C N F$ Films}

The PVA/CNF composite films were fabricated by using the solvent casting technique (Figure 1). PVA was first heated to dissolve in deionized water to obtain $8 \mathrm{wt} \%$ solution and were subsequently mixed with CNF dispersion in different ratios in a flask under vigorous stirring for $1.5 \mathrm{~h}$ to obtain the PVA/CNF hybrid solutions. Here, the weight content of CNF in the CNF/PVA nanocomposite solutions was varied from 0 to $2 \mathrm{wt} \%$ (based on the PVA solid weight). The mixed solutions were diluted to a solid content of $4 \mathrm{wt} \%$, and the same quantity of the mixed solutions was subsequently poured in the TFE molds with the same diameter and dried for $48 \mathrm{~h}$ at $25^{\circ} \mathrm{C}, 1 \%$ humidity. Eventually, a series of nanocomposites with different CNF contents was obtained. 


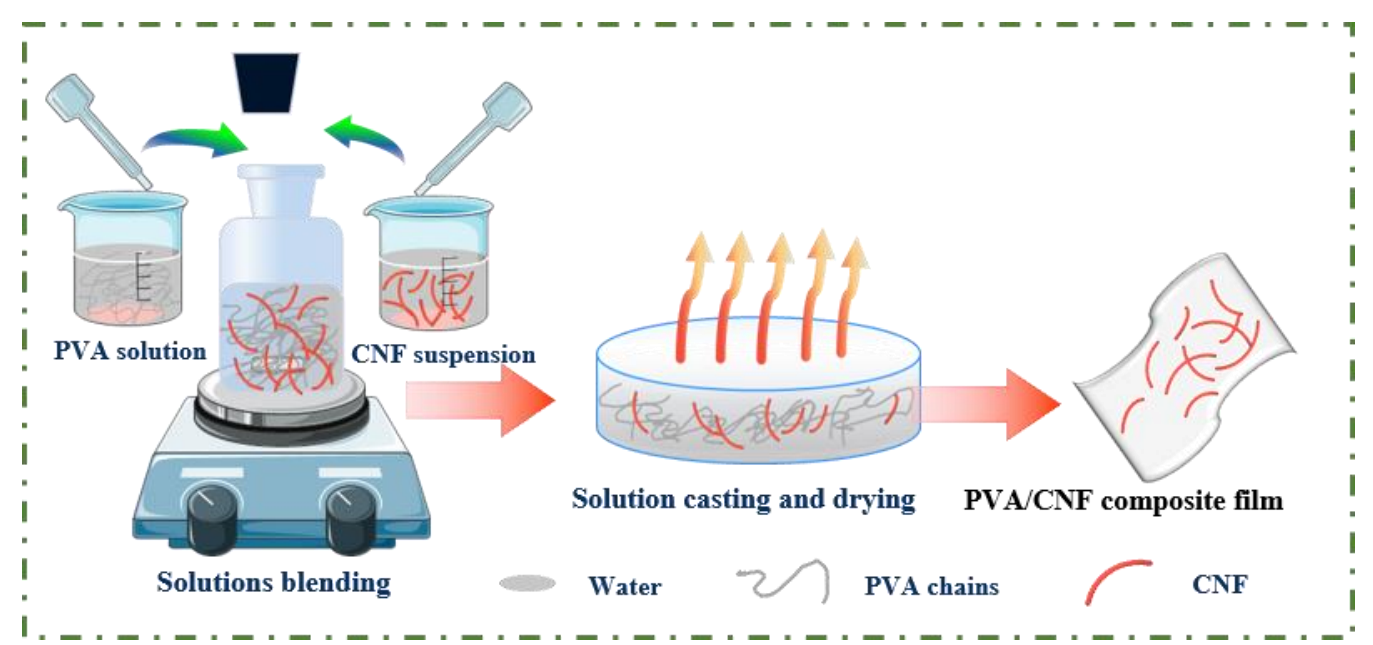

Figure 1. The schematic representation of the synthesis of the PVA/CNF nanocomposite films.

\subsection{Transmission Electron Microscopy (TEM)}

The CNF morphology was analyzed by using a transmission electron microscope (JEM-2100F, Japan JEOL Ltd, Beijing, China) equipped with a Gatan $1 \mathrm{k} \times 1 \mathrm{k}$ CCD camera. About $10 \mu \mathrm{L}$ CNF ethanol suspensions were deposited onto glow-discharged carbon-coated TEM grids.

\subsection{Fourier Transform Infrared Spectroscopy (FTIR)}

The FTIR spectra of polyvinyl alcohol, nanocellulose and the reinforced composites were acquired by using a Bruker Tensor II infrared spectrometer (Karlsruhe, Germany) in the range $400-4000 \mathrm{~cm}^{-1}$.

\subsection{Particle Size and Zeta Potential Measurement}

Zetasizer Nano ZS (Malvern Instruments Ltd., Malvern, UK) was used to measure the surface charge and estimate the size of the nanocellulose particles in aqueous suspension. The suspensions were diluted 1000 times and sonicated for $30 \mathrm{~min}$. The measurements were replicated 3 times, and an average value was presented. Additionally, the zeta potential distribution of the CNF suspensions was monitored with no ionic strength adjustment.

\subsection{Mechanical Properties}

The tensile analysis of the PVA film and nanocellulose reinforced PVA composites were carried out using an INSTRON 5966 electronic universal material testing machine (Boston, America), equipped with a $10 \mathrm{kN}$ load cell. The film specimens were cut in a rectangular shape with dimensions $40 \times 5 \mathrm{~mm}$ and a thickness of $0.2 \sim 0.3 \mathrm{~mm}$. The tensile measurements were conducted using a head speed of $6 \mathrm{~mm} \mathrm{~min}^{-1}$ and a span length of $10 \mathrm{~mm}$. Each membrane was tested at least 5 times under same conditions, and the average value were reported.

\subsection{Thermal Properties}

The thermal properties of the PVA/CNF composite films were evaluated using Discovery TGA 500 and DMA Q800 (TA, New Castle, DE, USA). The thermogravimetric analysis (TGA) of each sample (5-10 mg) was carried out in the temperature range $50-700{ }^{\circ} \mathrm{C}$, and the heating rate was set as $10{ }^{\circ} \mathrm{C} \mathrm{min}^{-1}$ under $\mathrm{N}_{2}$ purging $\left(30 \mathrm{~mL} \mathrm{~min}{ }^{-1}\right)$. The dynamic thermomechanical properties of the nanocomposites were analyzed using a heating rate of $3{ }^{\circ} \mathrm{C} \mathrm{min}^{-1}$ in the temperature range -50 to $100{ }^{\circ} \mathrm{C}$. 


\subsection{UV-Vis Spectra}

The visible light transmittance of the PVA/CNF films was determined in the wavelength range from 200 to $800 \mathrm{~nm}$ by using a PerkinElmer Lambda 950 UV-visible spectrophotometer, (Waltham, MA, USA).

\subsection{The Degree of Carboxylation of TEMPO-Oxidized CNFs}

The degree of carboxylation of TEMPO-oxidized CNFs was investigated by electric conductivity titration method [22,46]. Herein, $55.3 \mathrm{~g}$ CNF suspensions (containing $0.3 \mathrm{~g}$ $\mathrm{CNF}$ ) and $0.01 \mathrm{M} \mathrm{NaCl}$ solution $(5 \mathrm{~mL})$ were mixed and stirred sufficiently to prepare a welldispersed slurry. Then the above mixture was acidified with $0.1 \mathrm{M} \mathrm{HCl}$ solution and stirred again for $1 \mathrm{~h}$ at a $\mathrm{pH}$ value in the range of 2.5-3.0, thus ensuring all the carboxylate $\left(-\mathrm{COO}^{-}\right)$ to be changed to carboxyl groups $(-\mathrm{COOH})$ for further measurement. Subsequently, $0.04 \mathrm{M}$ $\mathrm{NaOH}$ solution was dropwise added at the rate of $0.1 \mathrm{~mL} / \mathrm{min}$ until $\mathrm{pH}=11$. During titration, conductivity meter was used to monitor the change of conductivity of solution in real-time. Finally, the titration curve of the $\mathrm{NaOH}$ consumption and conductivity was plotted, and the carboxylate content of the sample was determined from the titration curves. The content of carboxyl groups $(C)$ was determined using the following equation:

$$
C=\frac{\left(V_{2}-V_{1}\right) \times C_{\mathrm{NaOH}}}{m}
$$

where $V_{1}$ and $V_{2}$ are the volume of the used $\mathrm{NaOH}$ solution $(\mathrm{mL})$, corresponding to the intersection point of the linear fitting lines between the first and second stage and between the second and third stage, respectively. $\mathrm{C}_{\mathrm{NaOH}}$ represents the concentration of the $\mathrm{NaOH}$ solution $(0.04 \mathrm{M})$, and $m$ refers to the weight of the CNFs.

\section{Results and Discussion}

\subsection{Characterization of CNF with Different Lengths}

Nano-CNF with different lengths were fabricated by the TEMPO catalytic oxidation. The preparation method is a simple process and does not require the complex and expensive equipment. As observed from the TEM images of CNF20 (Figure 2a), CNF10 (Figure 2b) and CNF5 (Figure 2c), the diameters of the CNFs are in the nanoscale range, with the length successively increasing from a few hundred nanometers to a few microns. Figure $2 \mathrm{~d}$ respectively shows the optical images of the CNF films. As observed, the color of the different CNF films exhibits a significant distinction owing to the dimensional changes in CNFs.

During the TEMPO catalytic oxidation, $\mathrm{NaClO}$ reacts continuously with the jute fibers as an oxidant. Therefore, under certain $\mathrm{pH}$ conditions, the content of $\mathrm{NaClO}$ directly determines the degree of $\mathrm{CNF}$ reaction. The greater the amount of $\mathrm{NaClO}$, the more hydroxyl groups on C6 in the cellulose are oxidized. As a result, the TEMPO oxidation becomes more thorough, thus, reducing the length. Thus, the nanocellulose with different morphology and size can be designed by adjusting the addition of $\mathrm{NaClO}$.

CNF20 presents a uniform structure with a diameter of 5-10 $\mathrm{nm}$ and a length of several hundred nanometers to a few microns, thus, exhibiting a resultant aspect ratio of more than 50. Also, CNF10 exhibits a relatively uniform size under $200 \mathrm{~nm}$, which is larger in length as compared to CNF20. In addition, entanglements among the fibers are observed, which may be caused by the fact that a small amount of CNF are not completely peeled off and are still connected to each other. As noted from Figure 2c, the size of CNF5 is much larger than the other two, with the largest diameter up to tens of nanometers. The observed phenomenon may be due to the low concentration of $\mathrm{NaClO}$ leading to a lower degree of oxidation, thus, a majority of CNF are not been stripped out, thus, leading to a significant extent of non-nanoscale cellulose in the system. 

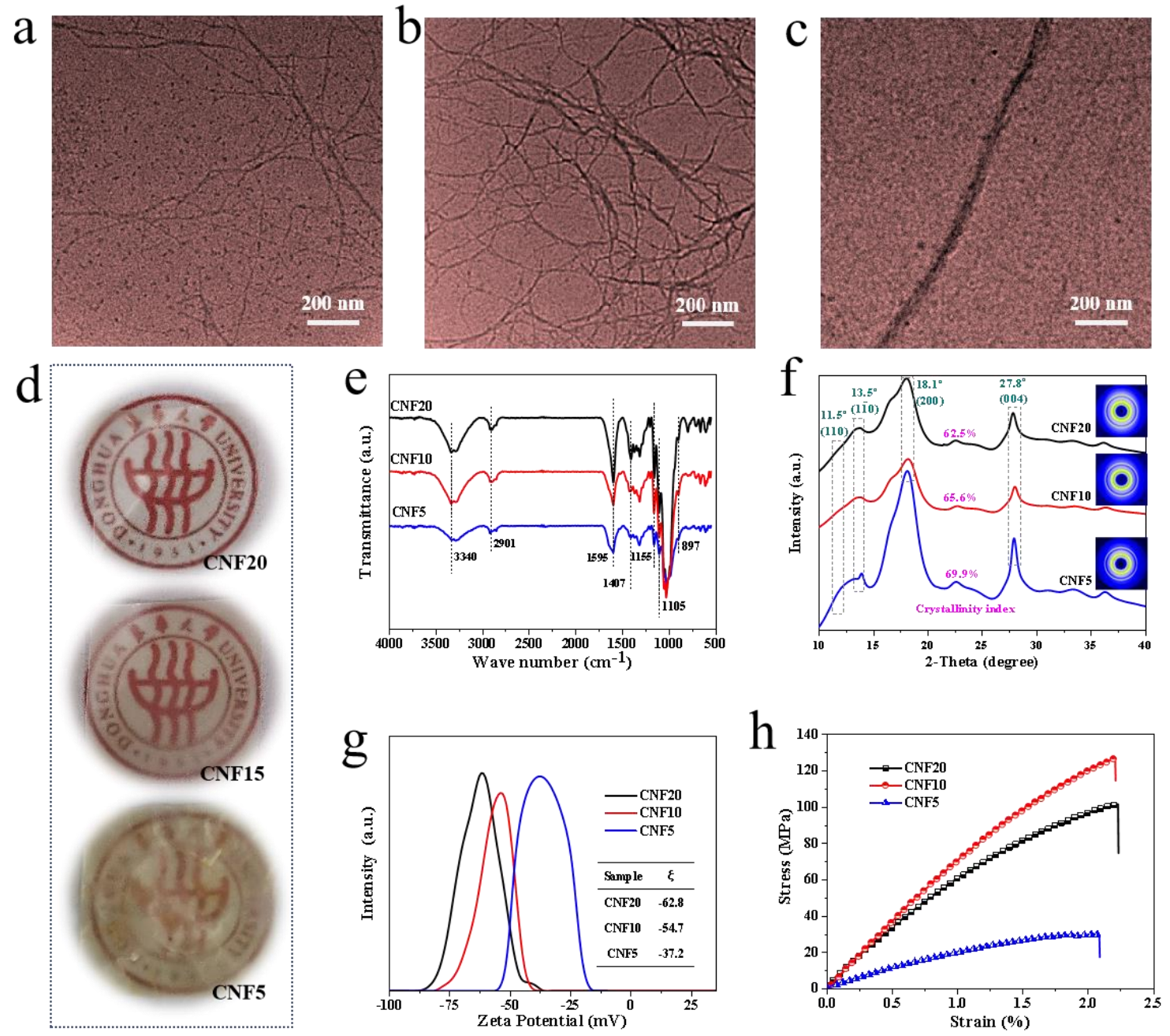

Figure 2. The TEM images: (a) CNF20; (b) CNF10; (c) CNF5; (d) Optical images of the films; (e) FTIR spectrum of CNF/PVA; (f) 1D-WAXS of CNF/PVA; (g) Zeta potential distribution of CNF/PVA; (h) Stress-strain curves of CNF/PVA.

The observed phenomenon was further confirmed by optical images of the films prepared using different nanocellulose materials. As can be observed from the Figure $2 \mathrm{~d}$, on increasing the $\mathrm{NaClO}$ dosage, the transparency of the CNF membrane is enhanced. For a low $\mathrm{NaClO}$ content, the size of the cellulose fibers is in the micron range (or even visible to the naked eye), thus, the macroscopic materials do not demonstrate an effective light transmittance. On increasing the proportion of $\mathrm{NaClO}$, the size of the cellulose fibrils reaches the nanoscale, and the CNF are closely packed with each other, thereby imparting optimal optical properties to the films.

As per the previous studies, changing the dosage of sodium hypochlorite does not affect the crystalline transformation of cellulose, with only change observed in the morphology and size of nanocellulose [47].

The characterization of the chemical structure, crystal structure and tensile properties of the different $\mathrm{CNF}$ materials are summarized in Figure $2 \mathrm{e}-\mathrm{f}$. As observed from the infrared spectra in Figure 2e, the nanocellulose materials exhibit the characteristic absorption peaks at 3340,2901, 1595, 1105, $898 \mathrm{~cm}^{-1}$ with slight differences in intensities among different samples $[48,49]$. It indicates that the chemical structure of CNF largely remains the same. Specifically, a strong absorption peak around $3300 \mathrm{~cm}^{-1}$ is observed, corresponding to the stretching vibration of the hydroxyl group [50]. The intensity of the $\mathrm{O}-\mathrm{H}$ stretching absorption peak was more pronounced for the CNF20 and CNF10 compared with CNF5, showing a higher proportion of cellulose within fibers [51]. The vibration peak at $2910 \mathrm{~cm}^{-1}$ 
is assigned to the $\mathrm{C}-\mathrm{H}$ stretching vibration of the methylene group, whereas the $\mathrm{C}-\mathrm{H}$ symmetric bending of $\mathrm{CH}_{2}$ appears at $1410 \mathrm{~cm}^{-1}$ [52,53]. At the same time, $\mathrm{CNF}$ exhibit characteristic bonds at 1595, 1105 and $898 \mathrm{~cm}^{-1}$, which are attributed to the stretching vibration of COONa derived by the TEMPO-mediated oxidization, $\mathrm{C}-\mathrm{O}-\mathrm{C}$ stretching of the ether bond and characteristic absorption of the cellulosic anomeric carbon $\mathrm{C} 1$, respectively [46-51]. Moreover, the intensity of the $\mathrm{COO}^{-}$peak exhibits the following order: CNF20 > CNF10 > CNF5, indicating the degree of carboxylation increased with increasing $\mathrm{NaClO}$ contents, which consists with conclusion of Puangsin et al [51,54].

Figure $2 \mathrm{f}$ presents the 1D integrated SR-WAXS curves of CNF20, CNF10 and CNF5. The integral curves display two strong diffraction peaks at $2 \theta=18.1^{\circ}$ and $27.8^{\circ}$, corresponding to the lattice planes of cellulose ((200) and (004)). Moreover, two overlapping weak diffraction peaks at $2 \theta=11.5^{\circ}$ and $13.5^{\circ}$ can be attributed to the Bragg peaks of cellulose ((110) and (110)). Overall, the different nanocellulose materials with various dimensions do not exhibit any changes in the crystalline structure.

The zeta potential is an important index representing the stability of a colloidal system, which manifests the degree of repulsion of the adjacent particles with the same charge in the dispersion. The higher is the absolute value of the zeta potential, the better is the stability of the colloidal dispersion. In other words, the ability to dissolve or disperse is higher than that of agglomeration [55]. The zeta potential distribution of CNF20, CNF10 and CNF5 is illustrated in Figure 2g. As observed, CNF20, CNF10, and CNF5 possess negative $\xi$ values, peaking at $-62.8,-54.7$ and $-37.2 \mathrm{mV}$, respectively. The absolute value of the zeta potential of nanocellulose is noted to increase with the $\mathrm{NaClO}$ addition, thus, indicating that the CNF dispersion becomes more electrically stable. It is due to the reason that a higher content of $\mathrm{NaClO}$ promotes the oxidation, so that a large number of primary hydroxyl groups on the surface of $\mathrm{CNF}$ are converted into $\mathrm{COO}^{-}$, and a strong electrostatic repulsion between the microfibers in water contributes to the uniform dispersion of CNF in the aqueous solution. The observed finding is consistent with the TEM observations.

The mechanical behavior of the CNF films is presented in Figure $2 \mathrm{~h}$. As observed from the stress-strain curve, CNF10 exhibits the best mechanical properties, with the tensile strength and Young's modulus reaching up to $126.38 \mathrm{MPa}$ and 7.4 GPa. In contrast, the tensile strength of CNF20 is $101.58 \mathrm{MPa}$, which is slightly lower than CNF10. On the other hand, its modulus is about 1.1 GPa lower than CNF10 (7.4 GPa). It is worth noting that the modulus of CNF5 is as low as $2.14 \mathrm{GPa}$, and the tensile strength is much lower as compared to CNF20 or CNF10, which may be attributed to the inhomogeneous dispersion of cellulose in the PVA matrix. In general, the CNF with different sizes exhibit completely different mechanical properties, which is important for exploring the different behaviors of the reinforced composites.

\subsection{Determination of the Content of Carboxyl Groups and Carboxylate in CNFs}

Figure $3 \mathrm{a}-\mathrm{c}$ shows the conductivity titration curves of CNFs with different dimensions. As is shown in Figure $3 a-c$, the relationship of the conductivity with the consumption of sodium hydroxide solution can be divided into three stages. With the increasing volume of sodium hydroxide, the conductivity decreases linearly in the first stage, changes slowly and tends to plateau in the second stage, and then begins to increase linearly in the third stage. The consumption of sodium hydroxide solution is directly relevant to the original carboxyl groups and the newly generated carboxyl groups from carboxylate after $\mathrm{HCl}$ acidification. According to the above Equation (1), the total content of carboxyl groups and carboxylate in CNFs can be calculated as $0.77 \mathrm{mmol} \mathrm{g}^{-1}, 0.75 \mathrm{mmol} \mathrm{g}^{-1}$ and $0.34 \mathrm{mmol} \mathrm{g}^{-1}$, respectively, which further demonstrates that more $\mathrm{NaClO}$ content promotes TEMPOmediated oxidation, and consequently increases the degree of carboxylation of CNF. 

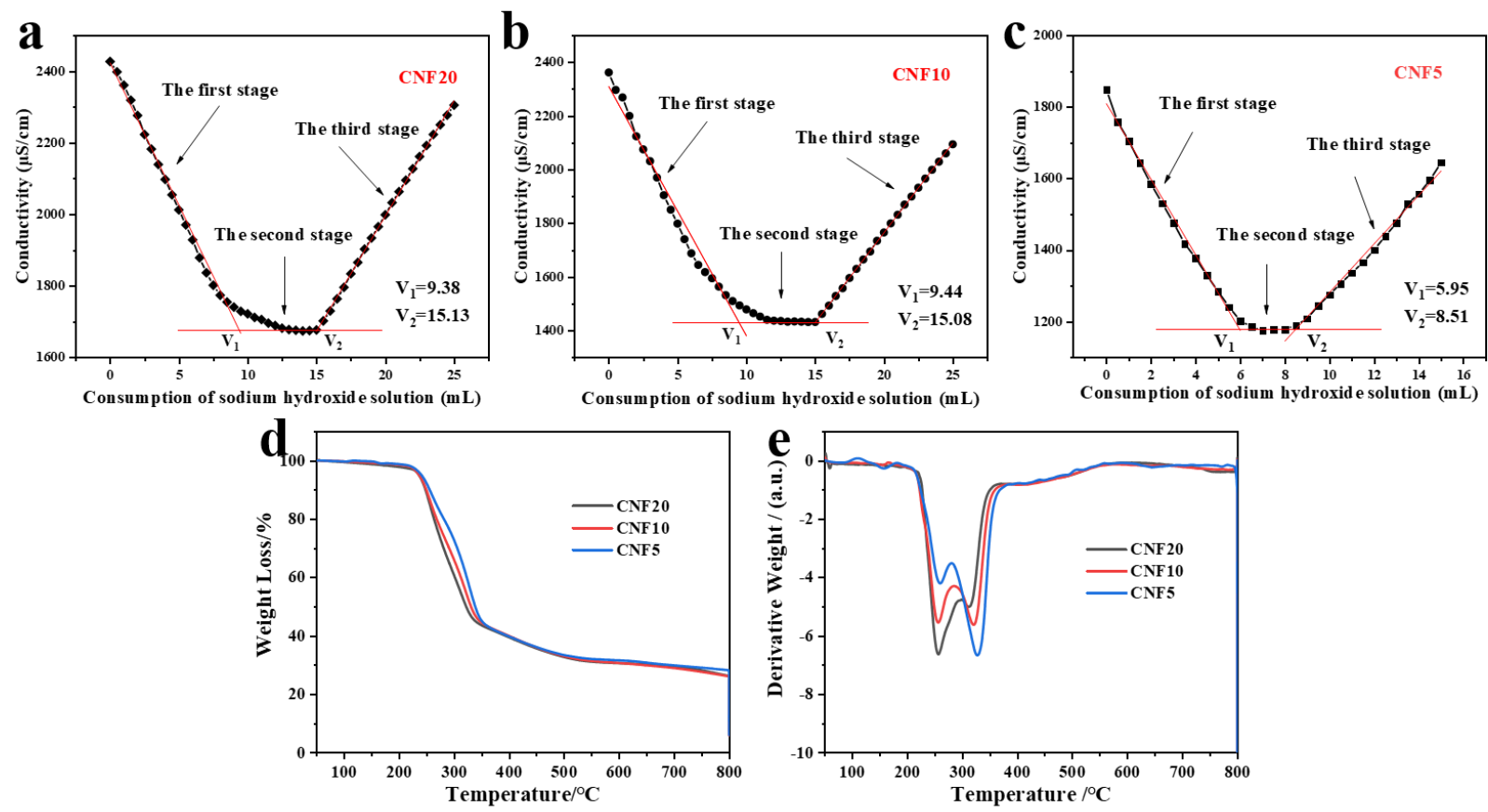

Figure 3. The conductivity titration curves $(\mathbf{a}-\mathbf{c})$, TGA curves (d), and DTG curves (e) of CNFs with different dimensions.

\subsection{Thermal Properties of CNFs with Different Lengths}

The thermogravimetric analysis (TGA) and derivative thermogravimetric (DTG) curves of CNFs are exhibited in Figure 3d-e. The degradation temperature $\left(\mathrm{T}_{\text {onset }}\right)$ and maximum degradation temperature $\left(\mathrm{T}_{\max }\right)$ are listed in Table 1 . The onset thermal degradation temperature of TEMPO-oxidized CNFs is $206.93,220.73,225.21^{\circ} \mathrm{C}$, respectively, which is lower than jute fiber $\left(>250^{\circ} \mathrm{C}\right)$. The lower degradation temperature of TEMPO-oxidized $\mathrm{CNFs}$ is attributed to decarboxylation of sodium anhydroglucuronate units and degradation of cellulose [51]. At the same time, the two main sharp peaks could be clearly observed from the DTG curves of CNFs, which represents the fastest degradation rate. According to Table 1 , the $\mathrm{T}_{\max 1}$ and $\mathrm{T}_{\max 2}$ of $\mathrm{CNF5}$ are all higher than CNF10 and CNF20. Besides, a higher content of residues at $800{ }^{\circ} \mathrm{C}(>25.0 \%)$ is observed for three kinds of CNFs, which is induced by a sodium cation acting as a counterion [56]. In conclusion, with the increase of sodium hypochlorite dosage, the carboxyl contents on cellulose surfaces increase and the decreased thermal stability connected with a higher residue content could be obtained [57].

Table 1. TGA data of CNFs with different morphology.

\begin{tabular}{ccccc}
\hline Samples & $\mathbf{T}_{\text {onset }} /{ }^{\circ} \mathbf{C}$ & $\mathbf{T}_{\max 1} /{ }^{\circ} \mathbf{C}$ & $\mathbf{T}_{\max 2} /{ }^{\circ} \mathbf{C}$ & Char Yield $/ \%$ \\
\hline CNF20 & 206.93 & 256.08 & 313.85 & 25.90 \\
CNF10 & 220.73 & 257.29 & 321.44 & 25.89 \\
CNF5 & 225.21 & 259.36 & 327.99 & 28.06 \\
\hline
\end{tabular}

\subsection{The Effects of Morphology and Dimension of CNF on PVA/CNF Composites}

\subsubsection{Chemical Strcture}

The differences in the chemical structure of PVA and CNF can be evaluated from the infrared spectra in Figure 4a. Both PVA and CNF exhibit strong absorption peaks around $3300 \mathrm{~cm}^{-1}$, which represents the stretching vibration of the hydroxyl group [58]. The absorption bonds at $2910 \mathrm{~cm}^{-1}, 1410 \mathrm{~cm}^{-1}$ and $1050 \mathrm{~cm}^{-1}$ are assigned to the $\mathrm{C}-\mathrm{H}$ stretching vibration of the methylene base, $\mathrm{C}-\mathrm{H}$ bending vibration peak of methylene and $\mathrm{C}-\mathrm{O}$ stretching, respectively [59]. On the other hand, the characteristic absorption peaks of CNF are observed at 1595, 1105 and $898 \mathrm{~cm}^{-1}$ [53], which are also consistent with 
Figure 2e. However, in the FTIR spectra of the PVA/CNF composite films, the characteristic absorption peaks of CNF are not obvious, owing to the small content of CNF.
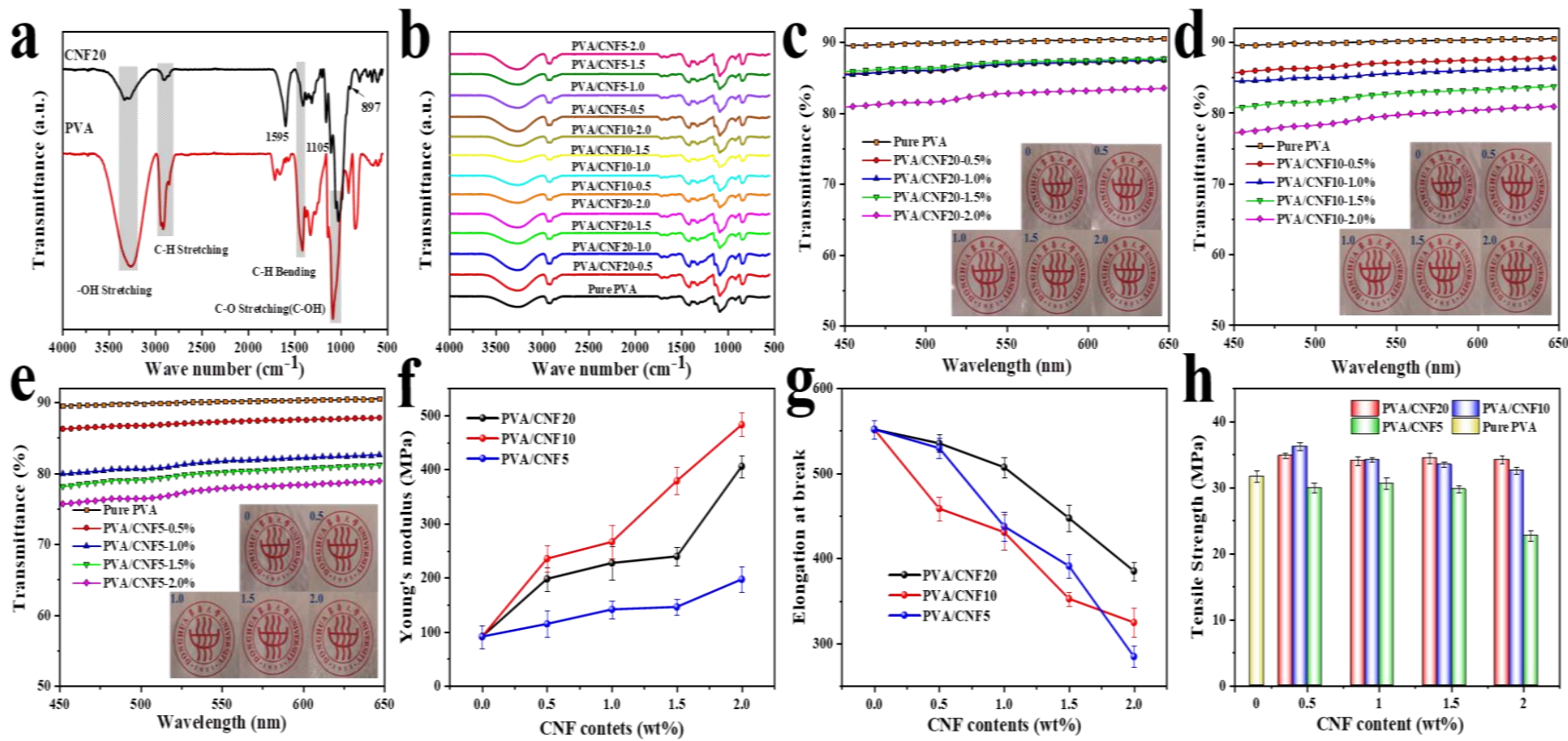

Figure 4. FTIR: (a) CNF20 and PVA films; (b) PVA/CNF composites with different additions of CNFs with different lengths; UV-vis spectrum of PVA/CNF composites: (c)PVA/CNF20;(d) PVA/CNF10; (e) PVA/CNF5; Mechanical properties of PVA/CNF composites: (f) Young's Modulus; (g) Elongation at break; (h) Tensile strength.

\subsubsection{Optical Transparency}

Owing to the superior optical transparency of the neat PVA films, the morphology of nanocellulose and its distribution in the PVA matrix play a dominant role in the visible light transmission of the nanocomposites [25]. The UV-vis spectra of the PVA/CNF nanocomposite films are presented in Figure $4 \mathrm{c}-\mathrm{e}$. The transmittance (Tr., \%) of pure PVA film is noted to be as high as $90 \%$, and the composite films also exhibit a remarkable optical transparency. Compared with the PVA/CNF10 and PVA/CNF5 composites, the PVA/CNF20 films display the highest optical transmittance for the same CNF concentration. The Tr. values of PVA/CNF20-0.5\%, PVA/CNF10-0.5\% and PVA/CNF5- $0.5 \%$ are determined to be $87.80 \%, 87.75 \%$ and $87.42 \%$, respectively, which are only about $3 \%$ lower than the transmittance of the pure PVA film (90.84\%). In addition, as also observed from the Figure $4 \mathrm{c}-\mathrm{e}$, the Tr. of PVA/CNF20-2\% and PVA/CNF10-2\% decreases to $83.51 \%$ and $80.51 \%$, respectively, while the light transmission of PVA/CNF5-2\% shows a remarkable decline to $77.55 \%$, thus, further indicating the effect of the uniform size of CNF20 as well as its perfect dispersion and distribution in the PVA matrix.

\subsubsection{Mechanical Properties}

Figure $4 \mathrm{f}-\mathrm{h}$ and Table 2 present the tensile modulus, tensile strength and elongationat-break of the composite materials. The typical stress-strain curves of the samples are also presented in Figure S1. 
Table 2. The tensile properties of pure PVA and PVA/CNF nanocomposites.

\begin{tabular}{ccccc}
\hline Film & $\begin{array}{c}\text { CNF Content } \\
(\mathbf{\%})\end{array}$ & $\begin{array}{c}\text { Tensile } \\
\text { Strength (MPa) }\end{array}$ & $\begin{array}{c}\text { Elongation at } \\
\text { Break (\%) }\end{array}$ & $\begin{array}{c}\text { Young's } \\
\text { Modulus (MPa) }\end{array}$ \\
\hline PVA & 0 & $31.65 \pm 0.85$ & $550.61 \pm 11.06$ & $91.00 \pm 21.64$ \\
& 0.5 & $34.84 \pm 0.44$ & $535.26 \pm 10.71$ & $197.73 \pm 22.03$ \\
PVA/CNF20 & 1.0 & $34.02 \pm 0.71$ & $507.12 \pm 11.65$ & $227.41 \pm 30.59$ \\
& 1.5 & $34.46 \pm 0.80$ & $447.24 \pm 15.49$ & $239.29 \pm 17.22$ \\
& 2.0 & $34.22 \pm 0.66$ & $385.04 \pm 10.73$ & $405.80 \pm 20.34$ \\
& 0.5 & $36.21 \pm 0.62$ & $458.49 \pm 13.85$ & $234.98 \pm 24.25$ \\
PVA/CNF10 & 1.0 & $34.21 \pm 0.33$ & $430.71 \pm 20.47$ & $266.22 \pm 30.66$ \\
& 1.5 & $33.48 \pm 0.43$ & $352.42 \pm 8.58$ & $378.88 \pm 25.25$ \\
& 2.0 & $32.55 \pm 0.56$ & $324.52 \pm 6.78$ & $482.75 \pm 21.95$ \\
PVA/CNF5 & 0.5 & $29.97 \pm 0.72$ & $529.64 \pm 11.06$ & $114.48 \pm 24.21$ \\
& 1.0 & $30.64 \pm 0.85$ & $437.54 \pm 11.75$ & $141.27 \pm 16.57$ \\
& 1.5 & $29.75 \pm 0.48$ & $390.89 \pm 17.21$ & $145.77 \pm 14.87$ \\
& 2.0 & $22.71 \pm 0.82$ & $284.42 \pm 12.48$ & $196.83 \pm 23.33$ \\
\hline
\end{tabular}

Compared to the raw PVA film, the Young's modulus of the PVA/CNF composite films display a significant increase as a function of the CNF content. Particularly, the tensile modulus of the PVA/CNF10 composites is observed to increase by $430 \%$ after the addition of $2 \%$ CNF10. A similar behavior is also observed for tensile strength, where a rising trend is noticed as a function of the nanocellulose loading. However, as the CNF content reaches $2 \%$, the tensile strength is observed to decrease slightly, probably owing to the poor distribution caused by the agglomeration of nanocellulose. Although a similar trend is noticed for the different nanocellulose materials, not all CNF materials are observed to generate a uniform reinforcement of the polyvinyl alcohol matrix. The incorporation of CNF5 results in a gradual decline in the tensile strength of the PVA composite film. The possible reason is that the presence of the non-nanoscale cellulose in CNF5 hinders its homogeneous dispersion in PVA and weakens the hydrogen bond interaction between $\mathrm{CNF}$ and PVA; thus, the polymer molecular chains cannot be compactly stacked, and the defects are easily formed. Besides, the elongation at break suffers a successive reduction on increasing the CNF content for all PVA/CNF nanocomposite films, which is attributed to the tough network structure formed between the cellulose nanofibirls, thus, thoroughly restricting the polymer chain activity [22,34].

\subsubsection{Thermal Properties}

The effect of CNF on the thermodynamic behavior of the PVA/CNF nanocomposites was characterized using thermogravimetric analysis (Figure 5). As observed, the samples exhibit a two-step thermal degradation, which is consistent with the degradation of PVA, as reported previously [60]. First, the dehydration reaction of PVA occurs at $220-350{ }^{\circ} \mathrm{C}$, as shown in the following equation:

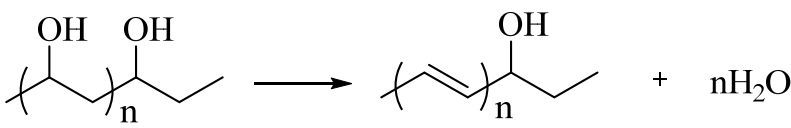

Second, the polyene residues degrade to form a mixture of carbon and hydrocarbons. The typical temperatures at $5 \%$ weight loss $\left(\mathrm{T}_{-5} \%\right.$ ) and $25 \%$ weight loss $\left(\mathrm{T}_{25 \%}\right)$ are used to study the thermal stability of the PVA composite films, as manifested in Table $3 . \mathrm{T}_{-5} \%$ of PVA is noted to be approximately $263^{\circ} \mathrm{C}$. Incorporating CNF (especially CNF20) in the PVA matrix shifts the $\mathrm{T}_{-5 \%}$ and $\mathrm{T}_{25} \%$ values toward higher temperatures, i.e., the thermal stability of the PVA films is improved on incorporating CNF20 and CNF10. Particularly, only $1 \%$ filler loading of CNF20 leads to a remarkable increase of $25^{\circ} \mathrm{C}$ in $\mathrm{T}_{25 \%}$, which can be attributed to the hydrogen bonds derived from CNF and PVA. The hydrogen bonds inhibit the movement of the polymer molecular chains, thereby forming a denser structure in the 
nanocomposites, which restricts the degradation of the PVA matrix [22,34,38]. However, the thermal stability of PVA/CNF5 is noted to decrease, as the thermal degradation of the non-nanoscale cellulose material accelerates the thermal decomposition of PVA [61-64].

Table 3. The TGA data of neat PVA and PVA/CNF composites as a function of the CNF content.

\begin{tabular}{cccc}
\hline Film & CNF Content (\%) & $\mathbf{T}-{ }_{\mathbf{5 \%}} /{ }^{\circ} \mathbf{C}$ & $\mathbf{T}_{\mathbf{2 5} \%} /{ }^{\circ} \mathbf{C}$ \\
\hline PVA & 0 & 263.07 & 367.21 \\
& 0.5 & 265.97 & 368.63 \\
PVA/CNF20 & 1.0 & 264.95 & 391.12 \\
& 1.5 & 262.94 & 376.18 \\
& 2.0 & 258.38 & 376.81 \\
PVA/CNF10 & 0.5 & 264.51 & 388.55 \\
& 1.0 & 262.27 & 368.36 \\
& 1.5 & 263.84 & 361.96 \\
PVA/CNF5 & 2.0 & 262.21 & 367.24 \\
& 0.5 & 258.25 & 358.17 \\
& 1.0 & 265.17 & 361.43 \\
& 1.5 & 262.56 & 357.07 \\
\hline
\end{tabular}

The high strength, dimensional anisotropy and biocompatibility of CNF make them a functional and renewable reinforcing agent for the polymer composites. The compatibility between the matrix and filler as well as the interfacial effect directly determine the composite properties. If the filler is not uniformly dispersed in the matrix or the interface adhesion with the matrix is weak, the mechanical properties of the composites cannot be enhanced or may even deteriorate. Thus, it is necessary to analyze the mechanical properties for exploring the affinity between the reinforcing agent and matrix as well as the relationship between the macro-performance and microstructure of the material [21]. The mechanical reinforcing effect of CNF in the PVA matrix was evaluated by using the conventional electronic universal testing and dynamic mechanical analysis (DMA).

Figure 6 and Table 4 exhibits the evolution of the storage modulus and $\tan \delta$ versus temperature for the PVA/CNF nanocomposite films as a function of the nanocellulose size and proportion (i.e., 0, 0.5, 1.0, 1.5 and $2 \mathrm{wt} \%$ ). As observed from the DMA curves and DMA data, a small extent (less than $1 \mathrm{wt} \%$ ) of CNF can make the storage modulus of the composite about 5-12\%. Once the CNF content reaches or even exceeds $1 \%$, a steady improvement in the viscoelasticity of the obtained nanocomposites is obtained, especially above the glass transition temperature (Tg). Specifically, PVA/ CNF5 showed the highest storage modulus (1453 MPa) when the CNF dosage was 1.0\%, while PVA/CNF20 exhibited $53.4 \%$ higher storage modulus than pure PVA when the dosage was $1.5 \%$. The CNF addition of $2.0 \%$ resulted in slightly lower storage modulus than that of $1.5 \%$. The observed enhancement trend might be associated with the restricted network structure formed by CNF in the PVA matrix [25]. 

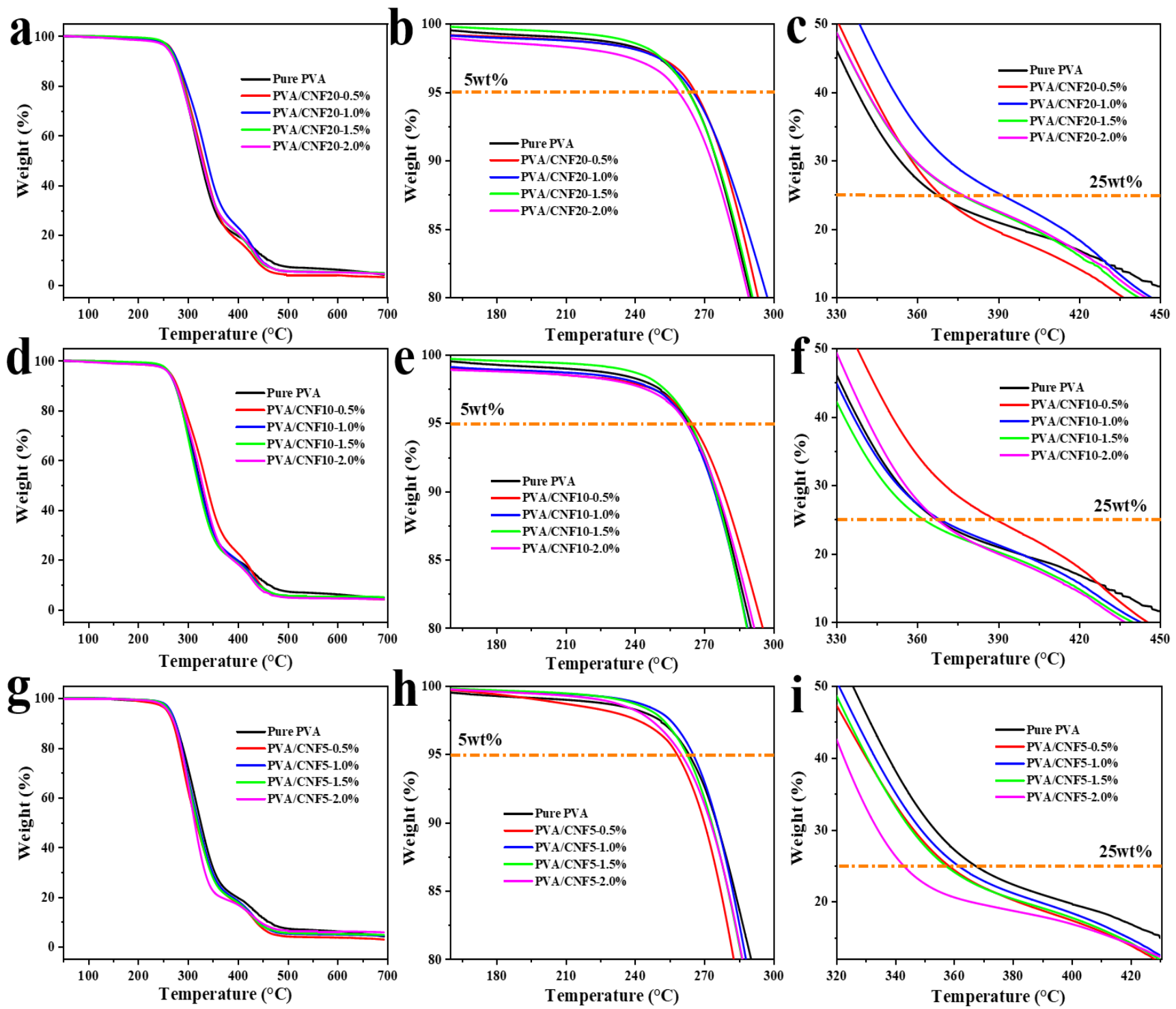

Figure 5. The TGA curves of (a-c) PVA/CNF20; (d-f) PVA/CNF10 and (g-i) PVA/CNF5 composites at a heating rate of $10^{\circ} \mathrm{C} \mathrm{min}^{-1}$.
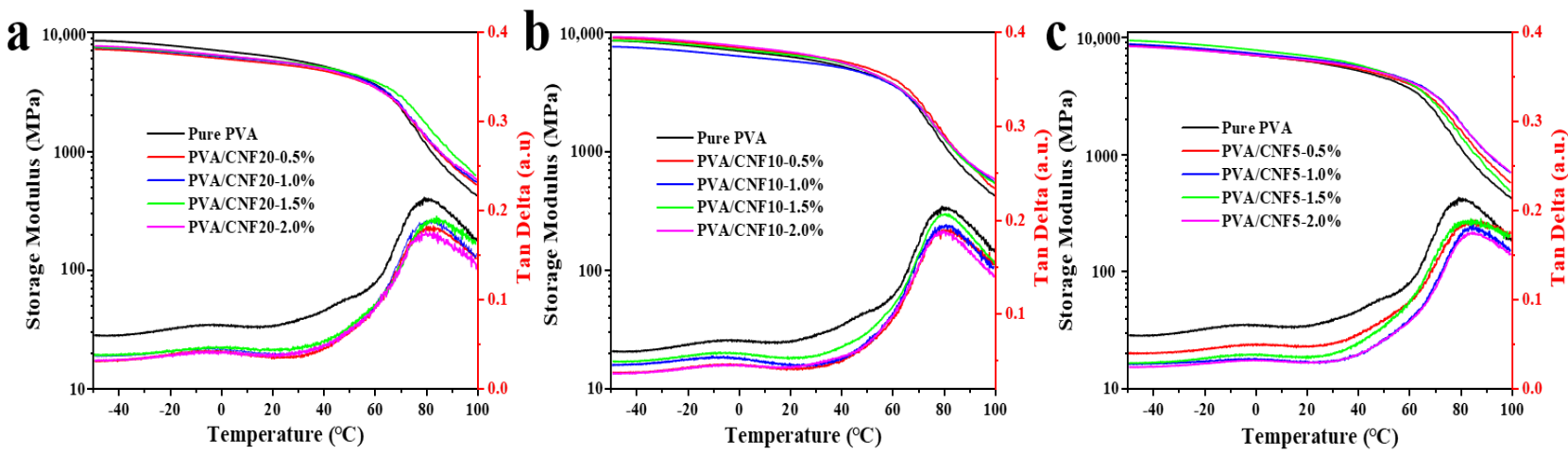

Figure 6. The DMA thermograms of neat PVA and PVA/CNF nanocomposites as a function of temperature: (a) PVA/CNF20; (b) PVA/CNF10; (c) PVA/CNF5. 
Table 4. The DMA data of PVA and PVA/CNF composites as a function of the CNF content.

\begin{tabular}{|c|c|c|c|c|c|c|c|c|c|c|c|c|c|}
\hline Samples & PVA & $20-0.5$ & $20-1.0$ & $20-1.5$ & $20-2.0$ & $10-0.5$ & $10-1.0$ & $10-1.5$ & $10-2.0$ & $5-0.5$ & $5-1.0$ & $5-1.5$ & $5-2.0$ \\
\hline $\mathrm{Tg} /{ }^{\circ} \mathrm{C}$ & 80 & 80 & 80 & 80 & 80 & 80 & 80 & 80 & 80 & 83 & 82 & 85 & 84 \\
\hline $\begin{array}{c}\Delta \mathrm{E}^{\prime} \text { at } \mathrm{Tg} \\
/ \mathrm{MPa}\end{array}$ & 1096 & 1225 & 1289 & 1681 & 1333 & 1156 & 1376 & 1173 & 1142 & 1263 & 1453 & 1030 & 1370 \\
\hline
\end{tabular}

\subsubsection{The Comparison of this Work with Other Researches}

The results of this work compared with other researches were summarized in Table 5. Compared PVA/MFC, the PVA/CNF films in this work possess lower tensile strength and lower Young's modulus, which may be attributed to the smaller diameter and lesser CNF content. However, the PVA/CNF composites exhibit higher tensile strength and higher Young's modulus contrast with EVA/CNF when the added CNF have similar size. In addition, the added CNF is CNF-I while the strength and modulus are lower than PVA/CNF-I, which can be caused by filming technology. In general, the PVA/CNF films in this work show relatively superior mechanical property, optical transparency and thermodynamic property, which will make them have a wide application prospect in the future.

Table 5. The results of this work compared with other researches.

\begin{tabular}{|c|c|c|c|c|c|c|c|c|c|c|c|c|c|}
\hline \multirow{2}{*}{ Samples } & \multicolumn{2}{|c|}{ CNF Morphology } & \multicolumn{2}{|c|}{$\sigma / \mathrm{MPa}$} & \multicolumn{2}{|c|}{$\varepsilon / \%$} & \multicolumn{2}{|c|}{ E/MPa } & \multicolumn{2}{|c|}{ Tr. $/ \%$} & \multicolumn{2}{|c|}{$\mathrm{T}_{\mathrm{d}} /{ }^{\circ} \mathrm{C}$} & \multirow[t]{2}{*}{ References } \\
\hline & $\mathrm{D} / \mathrm{nm}$ & $\mathrm{L} / \mathrm{nm}$ & After & Before & After & Before & After & Before & After & Before & After & Before & \\
\hline PVA/MFC & 365 & - & $48^{1}$ & 41 & - & - & $1600^{1}$ & 1200 & - & - & $265^{1}$ & 252 & [65] \\
\hline $\mathrm{EVA} / \mathrm{CNF}$ & $5-10$ & - & $3.64^{2}$ & 3.32 & $688^{2}$ & 750 & $6.92^{2}$ & 5.36 & $77^{2}$ & 78 & - & $320-380$ & [51] \\
\hline PVA/CNF-I & & 1120 & $44.30^{3}$ & 39.08 & $89.2^{3}$ & 320.5 & $1473.86^{3}$ & 96.09 & $53^{3}$ & & $294.9^{4}$ & 272.5 & \\
\hline PVA/CNF-II & 10-15 & 250 & $44.59^{3}$ & 39.08 & $313^{3}$ & 320.5 & $276.2^{3}$ & 96.09 & $86^{3}$ & 90 & $287.4^{4}$ & 272.5 & [25] \\
\hline PVA/CNF20 & $5-10$ & $200-1000$ & $34.22^{5}$ & & $385.04^{5}$ & & $405.80^{5}$ & & $83.51^{5}$ & & $258.38^{5}$ & & \\
\hline PVA/CNF10 & $10-15$ & $1000-3000$ & $32.55^{5}$ & 31.65 & $324.52^{5}$ & 550.61 & $482.75^{5}$ & 91 & $80.51^{5}$ & 90.84 & $262.21^{5}$ & 263.07 & This work \\
\hline PVA/CNF5 & $20-50$ & $>3000$ & $22.71^{5}$ & & $284.42^{5}$ & & $196.83^{5}$ & & $77.55^{5}$ & & $260.15^{5}$ & & \\
\hline
\end{tabular}

Abbreviations: $\sigma=$ Tensile Strength; $\varepsilon=$ Elongation at break; $\mathrm{E}=$ Young's Modulus; $\mathrm{Tr}$. = Transparency; $\mathrm{T}_{\mathrm{d}}=$ Thermal degradation temperature; $\mathrm{D}=$ Diameter; $\mathrm{L}=$ Length. ${ }^{1} \mathrm{CNF}$ content was $3 \% ;{ }^{2} \mathrm{CNF}$ content was $1 \% ;{ }^{3} \mathrm{CNF}$ content was $10 \% ;{ }^{4} \mathrm{CNF}$ content was $5 \% ;{ }^{5} \mathrm{CNF}$ content was $2 \%$.

\section{Conclusions}

In summary, a novel, simple and inexpensive strategy has been demonstrated for preparing the high performance polymer nanocomposites with tunable mechanical properties, based on the reinforcement of the PVA matrix with abundant and renewable CNF. Three kinds of CNF with different dimensions were produced by using the classical TEMPO catalytic oxidation by altering the $\mathrm{NaClO}$ content. The CNF grades exhibited distinct chemical structure, crystalline structure, light transmission, gel stability and mechanical properties. Subsequently, the reinforcement effect of the different CNF on the optical transparency, thermostability and mechanical properties of the PVA nanocomposites was thoroughly investigated. First, despite a decline in the optical transparency caused by CNF, the PVA/CNF films demonstrated a favorable visible light transmittance (Tr. $>75 \%$ ). Meanwhile, the inherent nature of $\mathrm{CNF}$, homogeneous dispersion and compatibility between PVA and CNF also had a significant impact on the mechanical properties and thermal stability of the PVA/CNF nanocomposite films. Due to the high strength and modulus of CNF10, the PVA/CNF films demonstrated a superior Young's modulus of $482.75 \mathrm{MPa}$ at $2 \mathrm{wt} \%$ filler loading. Further, the presence of CNF may induced the nucleation of the PVA matrix, which further contributed to the generation of the steady and robust 3D network.

Supplementary Materials: Supplementary information for this article can be found in the online version: https:/ / www.mdpi.com/article/10.3390/polym14010128/s1: Figure S1: Stress-Strain curves of pure PVA and PVA/CNF composites with various concentration of CNF.

Author Contributions: M.W., X.M. designed the experiments. M.W. performed the experiments, analyzed the characterized data and wrote the paper. X.M., H.L. and C.C. revised the paper. All authors have read and agreed to the published version of the manuscript. 
Funding: This work was financially supported by the National Key R\&D Program of China (No. 2020YFA0405800), the National Key R\&D Program of China (No. 2018YFB0704200), the National Key R\&D Program of China (No. 2021YFB3703900) and the Research Startup program of Donghua University (No. 285-07-005702).

Data Availability Statement: The data presented in this study are available upon request from the corresponding author.

Conflicts of Interest: The authors declare no conflict of interest.

\section{References}

1. Yun, Y.-H.; Eteshola, E.; Bhattacharya, A.; Dong, Z.; Shim, J.-S.; Conforti, L.; Kim, D.; Schulz, M.J.; Ahn, C.H.; Watts, N. Tiny medicine: Nanomaterial-based biosensors. Sensors 2009, 9, 9275-9299. [CrossRef]

2. Lalwani, G.; Patel, S.C.; Sitharaman, B. Two-and three-dimensional all-carbon nanomaterial assemblies for tissue engineering and regenerative medicine. Ann. Biomed. Eng. 2016, 44, 2020-2035. [CrossRef]

3. Wu, Z.; Wang, Y.; Liu, X.; Lv, C.; Li, Y.; Wei, D.; Liu, Z. Carbon-nanomaterial-based flexible batteries for wearable electronics. Adv. Mater. 2019, 31, 1800716. [CrossRef]

4. Kumar, L.Y. Role and adverse effects of nanomaterials in food technology. J. Toxicol. Health 2015, 2, 1-11. [CrossRef]

5. Joo, J.I.; Choi, M.; Jang, S.H.; Choi, S.; Park, S.M.; Shin, D.; Cho, K.H. Realizing cancer precision medicine by integrating systems biology and nanomaterial engineering. Adv. Mater. 2020, 32, 1906783. [CrossRef] [PubMed]

6. Shi, H.; Liu, W.; Xie, Y.; Yang, M.; Liu, C.; Zhang, F.; Wang, S.; Liang, L.; Pi, K. Synthesis of carboxymethyl chitosan-functionalized graphene nanomaterial for anticorrosive reinforcement of waterborne epoxy coating. Carbohydr. Polym. 2021, 252, 117249. [CrossRef]

7. Ghasemi, S.; Tajvidi, M.; Bousfield, D.W.; Gardner, D.J. Reinforcement of natural fiber yarns by cellulose nanomaterials: A multi-scale study. Ind. Crops Prod. 2018, 111, 471-481. [CrossRef]

8. Bilkar, D.; Keshavamurthy, R.; Tambrallimath, V. Influence of carbon nanofiber reinforcement on mechanical properties of polymer composites developed by FDM. Mater. Today Proc. 2021, 46, 4559-4562. [CrossRef]

9. Yano, H.; Omura, H.; Honma, Y.; Okumura, H.; Sano, H.; Nakatsubo, F. Designing cellulose nanofiber surface for high density polyethylene reinforcement. Cellulose 2018, 25, 3351-3362. [CrossRef]

10. Jiang, S.; Chen, Y.; Duan, G.; Mei, C.; Greiner, A.; Agarwal, S. Electrospun nanofiber reinforced composites: A review. Polym. Chem. 2018, 9, 2685-2720. [CrossRef]

11. Platnieks, O.; Gaidukovs, S.; Barkane, A.; Sereda, A.; Gaidukova, G.; Grase, L.; Thakur, V.K.; Filipova, I.; Fridrihsone, V.; Skute, M.; et al. Bio-Based Poly(butylene succinate)/Microcrystalline Cellulose/Nanofibrillated Cellulose-Based Sustainable Polymer Composites: Thermo-Mechanical and Biodegradation Studies. Polymers 2020, 12, 1472. [CrossRef]

12. Othman, S.H.; Wane, B.M.; Nordin, N.; Noor Hasnan, N.Z.; Talib, R.A.; Karyadi, J.N.W. Physical, Mechanical, and Water Vapor Barrier Properties of Starch/Cellulose Nanofiber/Thymol Bionanocomposite Films. Polymers 2021, 13, 4060. [CrossRef] [PubMed]

13. Katiyar, N.K.; Biswas, K.; Tiwary, C. Cryomilling as environmentally friendly synthesis route to prepare nanomaterials. Int. Mater. Rev. 2021, 66, 493-532. [CrossRef]

14. Kawamoto, M.; He, P.; Ito, Y. Green processing of carbon nanomaterials. Adv. Mater. 2017, 29, 1602423. [CrossRef] [PubMed]

15. Rai, G.K.; Singh, V. Study of fabrication and analysis of nanocellulose reinforced polymer matrix composites. Mater. Today Proc. 2021, 38, 85-88.

16. Basiuk, V.A.; Basiuk, E.V. Green Processes for Nanotechnology; Springer: Berlin/Heidelberg, Germany, 2015 ; p. 446.

17. Teo, H.L.; Wahab, R.A. Towards an eco-friendly deconstruction of agro-industrial biomass and preparation of renewable cellulose nanomaterials: A review. Int. J. Biol. Macromol. 2020, 161, 1414-1430. [CrossRef]

18. Moon, R.J.; Martini, A.; Nairn, J.; Simonsen, J.; Youngblood, J. Cellulose nanomaterials review: Structure, properties and nanocomposites. Chem. Soc. Rev. 2011, 40, 3941-3994. [CrossRef]

19. Nechyporchuk, O.; Belgacem, M.N.; Bras, J. Production of cellulose nanofibrils: A review of recent advances. Ind. Crops Prod. 2016, 93, 2-25. [CrossRef]

20. Salimi, S.; Sotudeh-Gharebagh, R.; Zarghami, R.; Chan, S.Y.; Yuen, K.H. Production of Nanocellulose and Its Applications in Drug Delivery: A Critical Review. ACS Sustain. Chem. Eng. 2019, 7, 15800-15827. [CrossRef]

21. Lee, H.; You, J.; Jin, H.-J.; Kwak, H.W. Chemical and physical reinforcement behavior of dialdehyde nanocellulose in PVA composite film: A comparison of nanofiber and nanocrystal. Carbohydr. Polym. 2020, 232, 115771. [CrossRef] [PubMed]

22. Wang, Z.; Qiao, X.; Sun, K. Rice straw cellulose nanofibrils reinforced poly (vinyl alcohol) composite films. Carbohydr. Polym. 2018, 197, 442-450. [CrossRef] [PubMed]

23. Naidu, D.S.; John, M.J. Cellulose nanofibrils reinforced xylan-alginate composites: Mechanical, thermal and barrier properties. Int. J. Biol. Macromol. 2021, 179, 448-456. [CrossRef]

24. Espinosa, E.; Bascón-Villegas, I.; Rosal, A.; Pérez-Rodríguez, F.; Chinga-Carrasco, G.; Rodríguez, A. PVA/(ligno) nanocellulose biocomposite films. Effect of residual lignin content on structural, mechanical, barrier and antioxidant properties. Int. J. Biol. Macromol. 2019, 141, 197-206. [CrossRef] 
25. Miao, X.; Tian, F.; Lin, J.; Li, H.; Li, X.; Bian, F.; Zhang, X. Tuning the mechanical properties of cellulose nanofibrils reinforced polyvinyl alcohol composites via altering the cellulose polymorphs. RSC Adv. 2016, 6, 83356-83365. [CrossRef]

26. Hamou, K.B.; Kaddami, H.; Dufresne, A.; Boufi, S.; Magnin, A.; Erchiqui, F. Impact of TEMPO-oxidization strength on the properties of cellulose nanofibril reinforced polyvinyl acetate nanocomposites. Carbohydr. Polym. 2018, 181, 1061-1070. [CrossRef]

27. Jabbar, A.; Militký, J.; Wiener, J.; Kale, B.M.; Ali, U.; Rwawiire, S. Nanocellulose coated woven jute/green epoxy composites: Characterization of mechanical and dynamic mechanical behavior. Compos. Struct. 2017, 161, 340-349. [CrossRef]

28. Chen, R.-D.; Huang, C.-F.; Hsu, S.-h. Composites of waterborne polyurethane and cellulose nanofibers for 3D printing and bioapplications. Carbohydr. Polym. 2019, 212, 75-88. [CrossRef] [PubMed]

29. Rana, A.K.; Frollini, E.; Thakur, V.K. Cellulose nanocrystals: Pretreatments, preparation strategies, and surface functionalization. Int. J. Biol. Macromol. 2021, 182, 1554-1581. [CrossRef]

30. Beluns, S.; Gaidukovs, S.; Platnieks, O.; Gaidukova, G.; Mierina, I.; Grase, L.; Starkova, O.; Brazdausks, P.; Thakur, V.K. From wood and hemp biomass wastes to sustainable nanocellulose foams. Ind. Crops Prod. 2021, 170, 113780. [CrossRef]

31. Ni, Y.; Li, J.; Fan, L. Production of nanocellulose with different length from ginkgo seed shells and applications for oil in water Pickering emulsions. Int. J. Biol. Macromol. 2020, 149, 617-626. [CrossRef]

32. Fukuzumi, H.; Saito, T.; Isogai, A. Influence of TEMPO-oxidized cellulose nanofibril length on film properties. Carbohydr. Polym. 2013, 93, 172-177. [CrossRef] [PubMed]

33. Li, T.; Li, M.; Zhong, Q.; Wu, T. Effect of Fibril Length on the Ice Recrystallization Inhibition Activity of Nanocelluloses. Carbohydr. Polym. 2020, 240, 116275. [CrossRef] [PubMed]

34. Mehrali, M.; Shirazi, F.S.; Mehrali, M.; Metselaar, H.S.C.; Kadri, N.A.B.; Osman, N.A.A. Dental implants from functionally graded materials. J. Biomed. Mater. Res. Part A Off. J. Soc. Biomater. Jpn. Soc. Biomater. Aust. Soc. Biomater. Korean Soc. Biomater. 2013, 101, 3046-3057. [CrossRef]

35. Lee, S.-Y.; Mohan, D.J.; Kang, I.-A.; Doh, G.-H.; Lee, S.; Han, S.O. Nanocellulose reinforced PVA composite films: Effects of acid treatment and filler loading. Fibers Polym. 2009, 10, 77-82. [CrossRef]

36. Gan, P.; Sam, S.; Abdullah, M.F.b.; Omar, M.F. Thermal properties of nanocellulose-reinforced composites: A review. J. Appl. Polym. Sci. 2020, 137, 48544. [CrossRef]

37. Nazrin, A.; Sapuan, S.; Zuhri, M. Mechanical, physical and thermal properties of sugar palm nanocellulose reinforced thermoplastic starch (TPS) / poly (lactic acid)(PLA) blend bionanocomposites. Polymers 2020, 12, 2216. [CrossRef] [PubMed]

38. El Miri, N.; Abdelouahdi, K.; Zahouily, M.; Fihri, A.; Barakat, A.; Solhy, A.; El Achaby, M. Bio-nanocomposite films based on cellulose nanocrystals filled polyvinyl alcohol/chitosan polymer blend. J. Appl. Polym. Sci. 2015, 132, 42004. [CrossRef]

39. Awad, S. Enhancing the Thermal and Mechanical Characteristics of Polyvinyl Alcohol (PVA)-Hemp Protein Particles (HPP) Composites. Int. Polym. Processing 2021, 36, 137-143. [CrossRef]

40. Awad, S.A.; Khalaf, E.M. Investigation of photodegradation preventing of polyvinyl alcohol/nanoclay composites. J. Polym. Environ. 2019, 27, 1908-1917. [CrossRef]

41. Begum, M.H.A.; Hossain, M.M.; Gafur, M.A.; KABIR, A.; Tanvir, N.I.; Molla, M.R. Preparation and characterization of polyvinyl alcohol-starch composites reinforced with pulp. SN Appl. Sci. 2019, 1, 1-9. [CrossRef]

42. Spagnol, C.; Fragal, E.H.; Witt, M.A.; Follmann, H.D.; Silva, R.; Rubira, A.F. Mechanically improved polyvinyl alcohol-composite films using modified cellulose nanowhiskers as nano-reinforcement. Carbohydr. Polym. 2018, 191, 25-34. [CrossRef] [PubMed]

43. Sameer, A. Investigation of Chemical Modification and Enzymatic Degradation of Poly (vinyl alcohol)/Hemoprotein Particle Composites. J. Turk. Chem. Soc. Sect. A Chem. 2021, 8, 651-658.

44. Zheng, Q.; Cai, Z.; Gong, S. Green synthesis of polyvinyl alcohol (PVA)-cellulose nanofibril (CNF) hybrid aerogels and their use as superabsorbents. J. Mater. Chem A 2014, 2, 3110. [CrossRef]

45. Isogai, A.; Saito, T.; Fukuzumi, H. TEMPO-oxidized cellulose nanofibers. Nanoscale 2011, 3, 71-85. [CrossRef]

46. Saito, T.; Isogai, A. TEMPO-mediated oxidation of native cellulose. The effect of oxidation conditions on chemical and crystal structures of the water-insoluble fractions. Biomacromolecules 2004, 5, 1983-1989. [CrossRef] [PubMed]

47. Song, L.; Miao, X.; Li, X.; Bian, F.; Lin, J.; Huang, Y. A tunable alkaline/oxidative process for cellulose nanofibrils exhibiting different morphological, crystalline properties. Carbohydr. Polym. 2021, 259, 117755. [CrossRef] [PubMed]

48. Zhbankov, R. Infrared Spectra of Cellulose and its Derivatives. In Consultants Bureau; Plenum Publishing Co.: New York, NY, USA, 1966.

49. Hermans, P.H. Physics and Chemistry of Cellulose Fibres; Elsevier: Amsterdam, The Netherlands, 1949; Volume 26, p. 683.

50. Chitbanyong, K.; Pitiphatharaworachot, S.; Pisutpiched, S.; Khantayanuwong, S.; Puangsin, B. Characterization of bamboo nanocellulose prepared by TEMPO-mediated oxidation. BioResources 2018, 13, 4440-4454. [CrossRef]

51. Tanpichai, S.; Wimolmala, E. Facile Single-step Preparation of Cellulose Nanofibers by TEMPO-mediated Oxidation and Their Nanocomposites. J. Nat. Fibers 2021, 1-17. [CrossRef]

52. Zhbankov, R.; Firsov, S.; Buslov, D.; Nikonenko, N.; Marchewka, M.; Ratajczak, H. Structural physico-chemistry of cellulose macromolecules. Vibrational spectra and structure of cellulose. J. Mol. Struct. 2002, 614, 117-125. [CrossRef]

53. Nicely, W.B. Infrared spectra of carbohydrates. In Advances in Carbohydrate Chemistry; Academic Press: Cambridge, MA, USA, 1957; Volume 12, pp. 13-33.

54. Puangsin, B.; Soeta, H.; Saito, T.; Isogai, A. Characterization of cellulose nanofibrils prepared by direct TEMPO-mediated oxidation of hemp bast. Cellulose 2017, 24, 3767-3775. [CrossRef] 
55. Pelissari, F.M.; Sobral, P.J.d.A.; Menegalli, F.C. Isolation and characterization of cellulose nanofibers from banana peels. Cellulose 2013, 21, 417-432. [CrossRef]

56. Kanai, N.; Honda, T.; Yoshihara, N.; Oyama, T.; Naito, A.; Ueda, K.; Kawamura, I. Structural characterization of cellulose nanofibers isolated from spent coffee grounds and their composite films with poly (vinyl alcohol): A new non-wood source. Cellulose 2020, 27, 5017-5028. [CrossRef]

57. Sánchez-Gutiérrez, M.; Espinosa, E.; Bascón-Villegas, I.; Pérez-Rodríguez, F.; Carrasco, E.; Rodríguez, A. Production of Cellulose Nanofibers from Olive Tree Harvest-A Residue with Wide Applications. Agronomy 2020, 10, 696. [CrossRef]

58. Kohli, D.; Garg, S.; Jana, A. Physical, mechanical, optical and biodegradability properties of polyvinyl alcohol/cellulose nanofibrils/kaolinite clay-based hybrid composite films. Indian Chem. Eng. 2021, 63, 62-74. [CrossRef]

59. Asad, M.; Saba, N.; Asiri, A.M.; Jawaid, M.; Indarti, E.; Wanrosli, W. Preparation and characterization of nanocomposite films from oil palm pulp nanocellulose/poly (Vinyl alcohol) by casting method. Carbohydr. Polym. 2018, 191, 103-111. [CrossRef]

60. Liu, D.; Sun, X.; Tian, H.; Maiti, S.; Ma, Z. Effects of cellulose nanofibrils on the structure and properties on PVA nanocomposites. Cellulose 2013, 20, 2981-2989. [CrossRef]

61. Waymack, B.E.; Belote, J.L.; Baliga, V.L.; Hajaligol, M.R. Effects of metal salts on char oxidation in pectins/uronic acids and other acid derivative carbohydrates. Fuel 2004, 83, 1505-1518. [CrossRef]

62. Raemy, A.; Schweizer, T. Thermal behaviour of carbohydrates studied by heat flow calorimetry. J. Therm. Anal. Calorim. 1983, 28, 95-108. [CrossRef]

63. Okita, Y.; Saito, T.; Isogai, A. Entire surface oxidation of various cellulose microfibrils by TEMPO-mediated oxidation. Biomacromolecules 2010, 11, 1696-1700. [CrossRef]

64. Jakab, E.; Mészáros, E.; Borsa, J. Effect of slight chemical modification on the pyrolysis behavior of cellulose fibers. J. Anal. Appl. Pyrolysis 2010, 87, 117-123. [CrossRef]

65. Tanpichai, S.; Sampson, W.W.; Eichhorn, S.J. Stress-transfer in microfibrillated cellulose reinforced poly (lactic acid) composites using Raman spectroscopy. Compos. Part A Appl. Sci. Manuf. 2012, 43, 1145-1152. [CrossRef] 